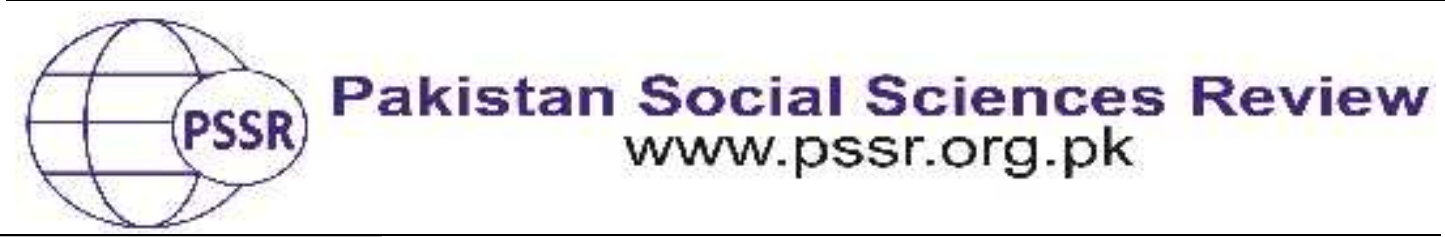

RESEARCH PAPER

\title{
Effect of Stretching Exercises on Flexibility of Male Athletes of Punjab University
}

\author{
Sajjad Ali Gill 1, Samavia Noor 2, Eqra Ahmed ${ }^{3}$
}

1. Lecturer,Department of Sports Sciences and Physical Education, The University of the Punjab, Lahore, Punjab, Pakistan

2. BS Student, Department of Sports Sciences and Physical Education, The University of the Punjab, Lahore, Punjab, Pakistan

3. BS Student, Department of Sports Sciences and Physical Education, The University of the Punjab, Lahore, Punjab, Pakistan

\begin{tabular}{|c|c|}
\hline PAF & $\Gamma$ \\
\hline $\begin{array}{l}\text { Rece } \\
\text { Febr } \\
\text { Acce } \\
\text { June } \\
\text { Onl } \\
\text { June }\end{array}$ & $\begin{array}{l}\text { This study investigated that the effects of stretching exercise on } \\
\text { the flexibility of male athletes. A sample size of }(\mathrm{N}=30) \text { selected } \\
\text { through simple random sampling method from population. The } \\
\text { intervention group comprised of }(\mathrm{N}=20) \text { subjects. The } \\
\text { population of the study was male athletes of Punjab University }\end{array}$ \\
\hline $\begin{array}{l}\text { ords: } \\
\text { lity, } \\
\text { of Motion } \\
\text { Reach Test } \\
\end{array}$ & $\begin{array}{l}\text { and } \\
\text { the } \\
\text { tes. } \\
\text { for }\end{array}$ \\
\hline Corr & $\begin{array}{l}\text { recurrence and resulted that interven } \\
\text { ary. The study is very beneficial for } \mathrm{m}\end{array}$ \\
\hline ja & to ease \\
\hline
\end{tabular}

\section{Introduction}

A precise definition of flexibility is "Ability of a joint to move with maximum range of motion". Flexibility is specific to individual joints, person to person and it also depend on exercises as well(Reese et al., 2016). One of the key fitness components is flexibility and considered among major components of physical fitness. Stretching related to physical fitness; it boosts blood flow and helps to perform better in workouts and competitions for athletes. During exercise muscles repeatedly contract and relax by performing functions at different joint (Dabbaghet al., 2018). Stretching exercises largely used, as the training or competition warm-up routine executed to prepare the musculoskeletal system before any sport performance (Yamaket al., 2018), due to stretching muscles extended and relax as it 
maximizes muscle engagement for the next workout (Abolhasani, 2018). There are further some types of stretching exercise like Static, Dynamic, Ballistic and Proprioceptive Neuromuscular facilitation (PNF stretching)etc (Hesselet al., 2017). In warm up we mostly use dynamic stretching exercises because it is easy to perform, but many studies suggest that this form of stretching during warm up has undesirable effects on performance (Strength, Power and Speed etc) (Jan \&Yaday, 2017) and mechanism involve in this form of performance decline is to involve both mechanical and neurophysiological changes (Tsolakiset al., 2010). So, in many studies researchers suggest that it's safe to use dynamic stretching routine before training or competition and it has a positive effect on performance because it increases core body temperature, stimulates nervous system and increases post-activation potentiation (Frederick \& Frederick, 2017; Flynn et al., 2018). Stretching also improves the blood flow throughout the body or toward the muscles involved in performing activities (Wickeet al., 2014). Stretching on regular basis not only enhanced the performance but pooled the blood circulation efficiently along with nutrients throughout the body and assisted to remove the harmful waste(metabolites) from the body, which eventually accelerate recovery time (Baxter et al., 2017). Thus, range of motion elevated with stretching, which enabled athletes to perform more dynamic tasks and boosts the techniques in sport-specific areas (Reese and Bandy, 2016). No matter whatever the athletes exercise background was, stretching is a universal weapon that can boost athletic development, and one that many elite athletes have adapted into their daily workout arrangements (Bernhart, 2013). Flexibility can improve with the correct technique of stretching, neuromuscular, coordination which also diminish feelings of stiffness along with reduction in delay onset muscle soreness (DOMS). Other potential pros of stretching boosted athletic performance with confidence and reducing of risk or muscle tears (Norris, 2015). Isolated stretching has a bigimportance in sports era,comprised of hamstrings muscles, hip flexors, quadriceps, calves and chest muscles (Singh, 2018). Proper technique of stretching will help to improve overall performance resulted in the lift of blood flow and decrease stiffness, in turn decline the risk of injury (McAtee, 2013). Flexibility boosts through stretching exercises is one of the basic tenets of physical fitness (Napoli, 2016). Stretching is the process of placing particular parts of the body into a position that will lengthen the muscles and their associated soft tissue(Baxter et al., 2017). The athletes have normal routine to make a habit of stretching before and after sessions,in addition correct exercises in order reduce risk of injury and increase performance (McHugh et al., 2010). Stretching keeps the muscles flexible, strong, and healthy, and we need that flexibility to maintain a range of motion in the joints, the muscles reduce range of motion and become less elastic (Baxter et al., 2017). The athletes, who did not perform any sort of flexibility and stretching exercises, have risk of joint pain, strains, and muscle damage (Shah \&Bhalara, 2012). 


\section{Hypothesis}

The study hypothesized that how the athlete improves their focus on stretching exercise routine after they know effects of different stretching exercises on flexibility and performance.

\section{Material and Methods}

The study comprised of male athletes of Punjab University $(\mathrm{N}=30)$. The average range of age was between the ages of (18 to 23)years and had not sustained a lower extremity injury within the past six months. Simple random sampling technique operated and experimental design along with pre\& post-exercisevaluation used for this study. Pre and post exercise evaluation design exploited by developmental researchers to determine the consequence of intervention on sample. The design was considered by two attributes,one attribute was the use of a single group of participants (a one-group design). This feature denotes that all participants werepart of a single condition that means all participants are given the same treatments and assessments. The other attribute was a straight ordering that requires the evaluation of a dependent variable before and after the treatment executed (pre and post-exercise evaluation). Within pre and post-exercise evaluation research, effects of a treatment were determined by calculating the difference between the first assessments of the dependent variable.

\section{Flow Chart}

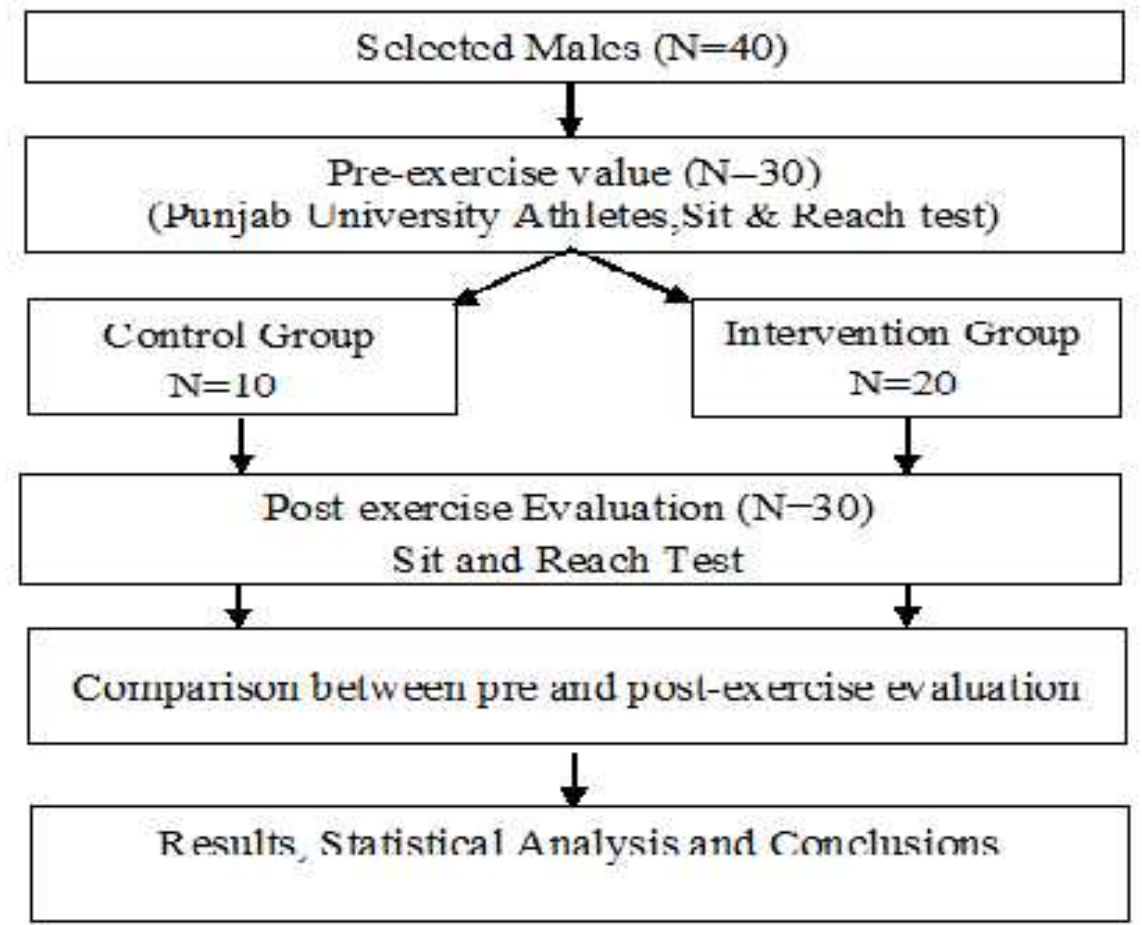




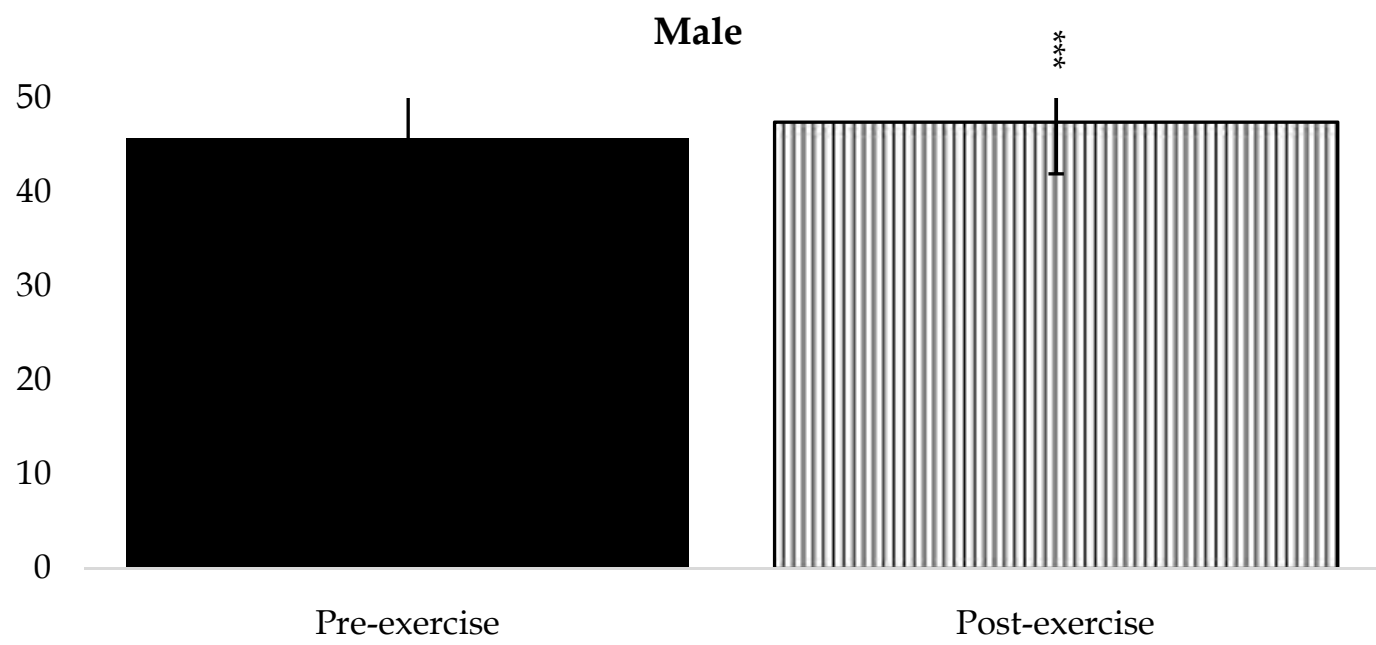

Figure 1. Shows research design flow chart of the activity

All subjects were volunteers and simple random selection method used for sampling. The independent variable was stretching exercises and dependent variable was Flexibility. The Punjab University athletes participated in this research and a samplerandom sampling procedure used to select the subjects. In addition, the study was within subject's design in which each subject served as their own control. The limitations of this study were that the results can only for the male athletes.

Table 1

Pre and Post-exercisevaluationobserved through paired sample t-test along with difference, percentage $t$-value and $p$-value

\begin{tabular}{ccccccc}
\hline Participants & \multicolumn{2}{c}{ Pre-exercise Post-exercise } & Diff (\%) & t value & p value & Cohens D \\
\hline \multirow{2}{*}{ Male } & \multirow{2}{*}{$45.8 \pm 5.4$} & $47.5 \pm 5.5$ & $\begin{array}{c}1.7 \\
(3.7)\end{array}$ & -18.9 & \multirow{2}{*}{0.000} & \multirow{2}{*}{3.55} \\
\hline
\end{tabular}

*** $\mathrm{p}<0.001$ highly significant

\section{Research Tool}

The testing instruments used in this study for flexibility (Sit and Reach Test) measurement. The sit and reach test is one of the simplesttest of flexibility which helps to measure the extensibility of the hamstrings, lower back and shoulder muscles and was described byWells and Dillon in 1952, It is probably the most used flexibility test and has a an easierprocedure for administer which requires minimal skills training for its application, perform on a large scale of population size in shorter period of time. A box with height, length, and width was $30 \mathrm{~cm}$ (12 inches) and the top of board with $22.86 \mathrm{~cm}$ (9 inches) lounged towards the feet place and a meter ruler used for the flexibility measurements. The flexibility measured in the inches and then converted to centimeters. The test was conducted in the Ground of Department of Sports Science \& Physical Education, University of the Punjab 
Lahore. The athletes performed this test on the Grass. Athletes were in proper kit at the time of test and their shoes were removed. Electronic Weight Machine was used to measure the weight of the subjects and heights were measured by measuring tape attached on wall along with age were asked from the subject.

\section{Discussion}

The main purpose of the study was exploring, effects of stretching exercises on flexibility on male athletes of university level as it was also reported by McHugh et al., 2010, Shah et al., 2012,McAtee, 2013,Jan \&Yaday, Singh, 2018, \& Pamboris, 2018. This study was limited to male athletes of Punjab University Lahore. Main research question was formulated in the relation to the objective of the study, which was to identify the effects of stretching exercises on flexibility on male athletes of university level.

\section{Conclusion}

It is concluded that the Major objective of the study was elaborating the effect of stretching exercise on the flexibility of male athletes. After careful treatment of the subjects and analysis of the pre-test and post-test measurements of flexibility of the male athletes, researcher concluded that the flexibility of male athletes improves after the training sessions of stretching exercises of 6 weeks. Results reveal that stretching exercises helps to improve flexibility and if properly and carefully use in warm up and cool down session it can improve performance and can enhance recovery period. Results also reveal that the flexibility of the player can be improved by different types of training such as dynamic stretching, PNF stretching, ballistic stretching. At the end researcher concluded that athletes should perform stretching exercises on regular bases in warm up and cool down session to enhance their flexibility and performance. Flexibility is beneficial andkey component that assists to reduce the risk of injury and improve athletic performance.

\section{Recommendations}

The study highly recommended that full body stretching is an essential part of the sports performance. It's not only helped in increase range of motion and reduction in injuries by absorbing external forces reaction to shoulders in upper body and pelvic region in lower body respectively. It also helped in decrease the recurrence rate. 


\section{Reference}

Abolhasani, E. (2018). Operant Conditioning of Human Upper-Limb Stretch Reflexes. Plumx Metrics.

Baxter, C., McNaughton, L. R., Sparks, A., Norton, L., and Bentley, D. (2017). Impact of stretching on the performance and injury risk of long-distance runners.Research in Sports Medicine, 25(1):78-90.

Bernhart, C. M. (2013).A review of stretching techniques and their effects on exercise. Plumx Metrics.

Dabbagh, A., Esmailian, F., and Aranki, S. (Eds.). (2018). Postoperative Critical Care for Adult Cardiac Surgical Patients. Springer

Flynn, S., Jellum, L., Howard, J., Moser, A., Mathis, D., Collins, C., and Watjen, C. (2018).Concepts of Fitness and Wellness.Nursing and Health Sciences.

Frederick, A., and Frederick, C. (2017). Stretch to win. Human Kinetics.

Hessel, A. L., Lindstedt, S. L., and Nishikawa, K. C. (2017). Physiological mechanisms of eccentric contraction and its applications: a role for the giant titin protein. Frontiers in physiology, 8(70): 1-14.

Jan, M., and Yaday, J. S. (2017).A Comparative Study on Effect of Selected Exercises on Flexibility and Co-Ordination of Badminton and Tennis Players.4(3):139-142.

McAtee, R. E. (2013). Facilitated stretching.Human Kinetics.

McHugh, M. P., and Cosgrave, C. H. (2010). To stretch or not to stretch: the role of stretching in injury prevention and performance. Scandinavian journal of medicine \& science in sports, 20(2): 169-181.

Norris, C. M. (2015).The complete guide to stretching.Bloomsbury Publishing.

Olivier, M. H., Horan, S. A., Evans, K. A., and Keogh, J. W. (2016). The effect of a seven-week exercise program on golf swing performance and musculoskeletal measures. International Journal of Sports Science \& Coaching, 11(4): 610-618.

Pamboris, G. M. (2018). An investigation into the mechanisms of acute effects of dynamic stretching on ankle joint mechanics and running economy (Doctoral dissertation, Brunel University London).

Reese, N. B., and Bandy, W. D. (2016).Joint range of motion and muscle length testing-E-book. Elsevier Health Sciences. 
Shah, S., andBhalara, A. (2012). Myofascial Release as an Effective Massage Therapy Technique. Gujarat: SPB Physiotherapy College, Ugat-Bhesan Road, Surat

Schiller, B., Colgan III, W., Calderon, B., \& Johnson, B. R. (2018). Muscle Spindles and Our Sense of Physical Self: Kinesthetic Illusions of Limb Position and Posture. Journal of Undergraduate Neuroscience Education, 16(3): A282.

Shah, S., and Bhalara, A. (2012).Myofascial release.Inter J Health Sci Res, 2(2):6977.

Singh, M. K. I. (2018). Effectiveness of myofascial release on balance and flexibility in sepak takraw players (Doctoral dissertation, Pusat PengajianSainsPerubatan, UniversitiSains Malaysia).

Smith, D. A. (2018). The sliding-filament theory of muscle contraction. Springer International Publishing.

Wicke, J., Gainey, K., and Figueroa, M. (2014).A comparison of self-administered proprioceptive neuromuscular facilitation to static stretching on range of motion and flexibility. The Journal of Strength \& Conditioning Research, 28(1): 168-172.

Yamak, b., imamoglu, o., islamoglu, i., and cebi, m. (2018). The effects of exercise on body posture. Electronic turkish studies, 13(18):1377-1388. 